\title{
Study on Brand Mismatching toward the Acquiring Enterprise Brand Dilution-Based on a Prospective of Construal Level Theory
}

\author{
Guangmin Zhai, Xinhong Liang, Haiquan Chen \\ School of Management, Jinan University, Guangzhou, China \\ Email: zhgm262510@163.com
}

Received 31 May 2016; accepted 2 July 2016; published 5 July 2016

Copyright (C) 2016 by authors and Scientific Research Publishing Inc. This work is licensed under the Creative Commons Attribution International License (CC BY). http://creativecommons.org/licenses/by/4.0/

\section{(c) (i) Open Access}

\begin{abstract}
During the cross-border mergers and acquisitions process, there are numerous factors that affect the brand evaluation of acquiring enterprise, one important factor is brand matching between acquiring and target enterprises. Experiments draw conclusions that dilution does exist and construal level can moderate the negative impacts. These findings warn Chinese managers that brand mismatching between cross-border M \& A may dilute the brand of acquiring enterprises.
\end{abstract}

Keywords

Cross-Border Mergers and Acquisitions, Brand Mismatching, Brand Dilution, Construal Level

\section{Introduction}

Cross-border M \& $\mathrm{A}$ is acquiring enterprise who wants to achieve a certain purpose by certain channels and means of payment. They buy all the assets of target enterprise or buy enough to exercise the operational activities of the shares to implement actual or complete control of behavior. It can help acquiring enterprise to reduce barriers to enter a new industry and expand market share. In the modern society, Chinese enterprises cross-border M \& A is very common. In December 2012, state-owned holding company CNOOC paid \$15.1 billion for acquisition of Canada Nixon company which was the largest cross-border M \& A of Chinese companies. Although cross-border M \& A can bring huge competitive advantages, and on the surface of both sides it is a winwin strategy. It can bring many adverses, including acquiring enterprises brand dilution. 
Brand dilution refers to positive attitudes or comments of acquiring enterprises to decline in the cross-border M \& A. There are many factors that will affect consumers' cognition, emotion and attitude to acquiring enterprises. Park (1996) said brand fit was an important factor that affected consumers evaluation to acquiring enterprises, chose a brand with high reputation and did not guarantee the success of cross-border M \& A [1]. Baumgarth (2004) raised that consumers had positive attitude toward the joint brand when brand matching degree was high [2]. From the above studies, acquiring enterprises do not always have bright future; they may be limited by brand dilution.

Acquiring and target enterprises are very familiar with the brands for consumers. However, both are significantly different in such aspects as market image. Therefore, we choose China domestic brands and international brands as research subjects. This research is very important for the brand strategy decision-makers, because it helps them recognize the existence of the brand dilution effects and knows how to prevent and reduce negative impacts.

\section{Theoretical Background}

\subsection{Literature Review of Matching}

Matching refers to suitability and degree between things, it is consumers' social perception after brands combination [3]. Keller (1993) argued that brand matching is consistency of consumers' perceptions of brands cooperation. Alba (1994) pointed out that consumers would evaluate the brand on the basis of brand awareness; Ruth and Simonin (1998) found that if the matching degree of two brands is higher, the higher consumer gave his evaluation of co-branding. If consumers perceived mismatching, they would gave low evaluation to joint brands. Domestic scholars Lu Changbao (2009) argued that matching included three categories: product matching, market matching and brand matching [4]. We define brand matching between acquiring and target enterprises as consistence of brand core value and brand image.

\subsection{Literature Review of Brand Dilution}

Brand dilution is weakness of brand cognition, including uglification and fuzziness. Defacing is consumers negative strengtheness of brand association which will affect consumers' perception of brand image. Fuzziness is attenuation of the consumers' positive brands association which will reduce the associations of brand uniqueness. In cross-border M \& A, if target enterprise' brand image and brand core value do not match with acquiring enterprise, it will inspire fuzzy mechanism of brand dilution and affect consumers' perception.

\subsection{Literature Review of Construal Level}

Liberman and Trope (1998) raised temporal construal level theory which was the earliest origin of construal level theory. Wakslak (2006) proposed construal level theory with wide influence, and social distance, spacial distance and possibility are collectively referred to as psychological distance [5]. Kim and John (2008) put forward that relatively close space, time and social distance, higher possibility of context, individual was more likely to adopt low construal level. On the contrary, individual was more likely to take high construal level [6]. In the study of brand extension we found that when evaluated brand extension, consumers with high construal level give more weight than consumers with low construal level. The reason is that sense of matching needs high abstraction.

Construal level theory gives us inspiration and helps us to theoretically describe and explain situation of cross-border M \& A. There are potential dilution risks for acquiring enterprises when their brand image and core value do not match with target enterprise.

\section{Research Model and Hypothesis}

\subsection{Research Model}

Based on the above theoretical background, we add construal level theory to research model (as shown in Figure 1). Brand image and core value mismatching between acquiring and target enterprises will affect consumers' evaluation to acquiring enterprise brand. Construal level adjusts effects of acquiring enterprise evaluation. 


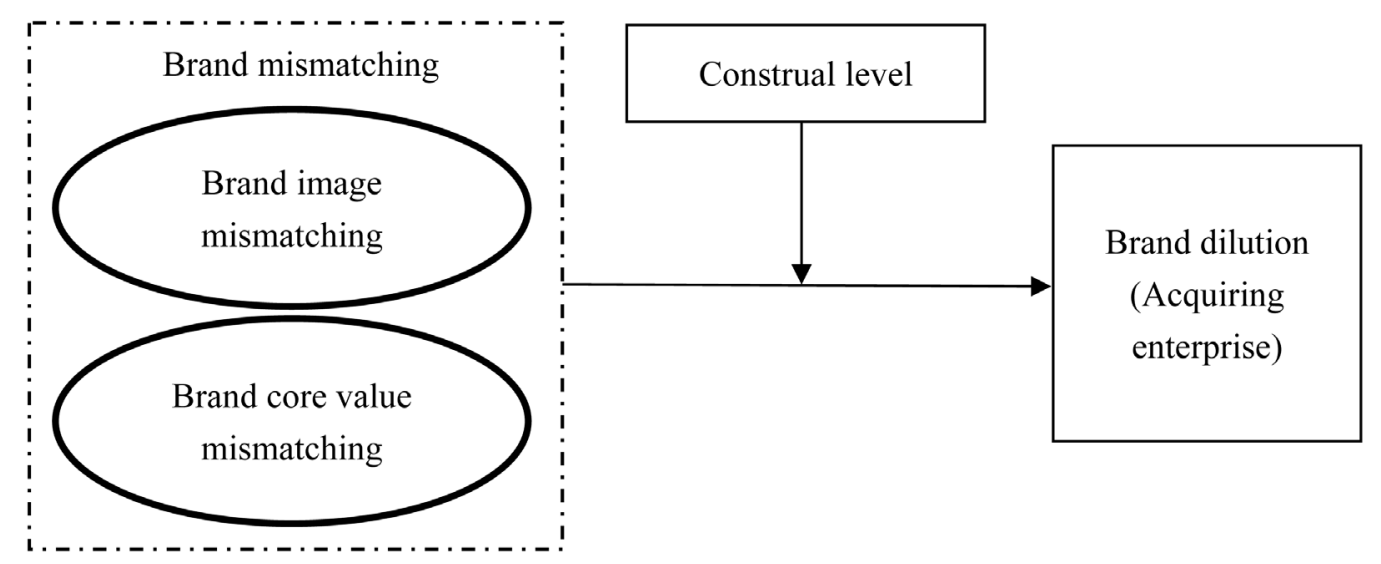

Figure 1. Theoretical model.

\subsection{Research Hypothesis}

1) Brand image mismatching affects evaluation or attitude to acquiring enterprise brand

Keller (1993) thought brand image was consumers' perception reflected by brand association. It was closely tied with brand qualities and brand preference [6]. Brand image had an effect on consumers' purchase decision. Some scholars further pointed out that when acquiring enterprise mergered a target enterprise whose brand image was not consistent, consumers started the attribution of search to look for reasons, this attribution of search may lead to bad evaluation to acquiring enterprise brand. Therefore, we put forward the following research hypothesis:

H1: Brand image mismatching of acquiring and target enterprise scan reduce brand evaluation or attitude to acquiring enterprise. Namely, the more mismatching between two brand images, the more brand dilution to acquiring enterprise.

2) Brand core value mismatching affects evaluation or attitude to acquiring enterprise brand

Brand core value refers to a brand promising and delivering to consumers the most important, the most different and persistent rational, emotional and symbolic value [1]. Information integration theory and emotion migration model tell us that when faced with cross-border $\mathrm{M} \& \mathrm{~A}$, consumers firstly recall all brand information of target enterprise, then migrate judgement to acquiring enterprise brand. when there is mismatching between acquiring and target enterprises brand core values, consumer tend to make negative evaluation. Therefore, we put forward the following hypothesis:

H2: Brand core value mismatching of acquiring and target enterprises can reduce brand evaluation or attitude to acquiring enterprise. Namely, the more mismatching between two brand core values, the more brand dilution to acquiring enterprise.

3) Construal level moderates effects brand mismatching on acquiring enterprise brand evaluation

Matching is interpretation and evaluation of two things which cognitive subject gives. This kind of interpretation and evaluation can be either at the specific level or at the abstract level, construal level that represents congnition abstract level can have an influence on matching. In cross-border M \& A, consumers' matching perception of brand core value between acquiring and target enterprises depends on whether two enterprises use specific and detailed information, matching perception of brand image relies on whether use abstract and integral information. In the low construal level, core value mismatching reflecting detailed and specific information will be strengthened. In the high construal level, image mismatching reflecting overall and abstract information will be strengthened. Therefore, we put forward the following hypothesis:

H3: In the low construal level, brand dilution core value mismatching causes is greater than image mismatching to acquiring enterprise.

H4: In the high construal level, brand dilution image mismatching causes is greater than core value mismatching to acquiring enterprise.

These hypotheses do not mean that cross-border M \& A will always damage acquiring enterprise, we cannot deny its benefits. It is pointed out that acquiring enterprises not only have many benefits, but also have potential negative impacts. 


\section{Research Design}

In order to test the proposed model, we use real, not imaginary brands. Because feelings and associations of real brands can be activated. At the same time, it is necessary to use multiple brands, so that were little on brands we choose and increase external validity.

\subsection{Test Design}

Experiments use domestic car brands, because this kind of M \& A is very popular in China. Some well-known domestic brands are eager to improve their brand value and expand oversea market.

According to Gwinner (1999) the definition of brand image matching, brand core value matching [7]. We form two kinds of mismatching by group discussion. Brand image mismatching refers to brand awareness, brand quality, and brand preference matching score of two enterprises is low. Brand core value mismatching refers to difference and rational, emotional and symbolic value of sustainability two enterprises promising to consumers matching score is low.

\subsection{Test Process and Variable Measurement}

Subjects $(n=100)$ are mainly MBA students from a university, five postgraduates participating in the group interview. Participants were randomly assigned to read two kinds of brand mismatching materials and answer a few questions. These questions mainly involve variables such as attitude or evaluation to acquiring enterprises and construal level. Then let them make evaluation of cross-border M \& A, the results show that for Geely and Volvo brand image rating is as follows (M Geely $=3.42$, seven subscales, M Volvo $=5.43$ ), score of brand core value is (M Geely $=4.57$, seven subscales, M Volvo $=4.98)$. For Saic and Ssangyong, score of brand core is as follows (M Saic = 4.12, seven subscales, MSsangyong = 5.23), score of brand image is as follows ( $\mathrm{M}$ Saic = 4.54 , seven subscales, MSsangyong $=4.89$ ). Therefore, Geely and Volvo can be respectively used to examine effects brand image mismatching to acquiring anterprises. Saic and Ssangyong are used to examine effects brand core value mismatching to acquiring enterprises.

We use Vallacher and Wegner's (1987) action identification scale as a measurement of personality trait construal level [8]. Specific method is as follows: please read action recognition scale, the subjects of 25 kinds of behavior in the interpretation of high level item and low level item, selecting from the high level explain item combined as participants explain the scores level. According to Kim and John (2008), average segmentation method is used to slit the participants construal level. Specifically, participants whose scores of construal level greater than or equal to 14 points are divided into high level group; otherwise, less than 14 points are classified as low construal level group. Finally asking participants to fill out basic demographic characteristics of the data including age, sex.

\subsection{Data Analysis and Hypothesis Testing}

Experiment was conducted in a university, 100 MBA students are randomly distributed to two kinds of materials about brand mismatching. After carefully reading, students need to finish the questions. 94 valid questionnaires are received. 34 are females and 60 are males, age distribution is 28 to 37.

1) Analysis of reliability and validity

Confirmatory factor analysis of brand image mismatching, brand core value mismatching and acquiring enterprise evaluation showed that measurement model fitting index X2/df = 1.85 (reference value is less than 3); $\mathrm{GIF}=0.90(\mathrm{rv}>0.9)$; CIF $=0.906$ (rv > 0.9); RMSEA $=0.09$ (rv < 0.1), basically reach the standard of reference which mean that model fits well. In addition to some items, the standardization of each item on the factor load is above 0.58 which shows that scale has good validity. Cronbach a coefficient of each variable is 0.71 , 0.86, 0.79 which means that scale reliability meets the requirements.

2) Dilution effects brand mismatching have on acquiring enterprise brand

We take attitude differences before and after tests as the dependent variable (dilution effect to acquiring enterprise) to do variance analysis. Attitudes before and after tests (Geely) are respectively 4.29 and 3.78 when faced with brand image mismatching and significantly different $(P<0.05)$ which suggests that acquiring enterprise has brand dilution. Attitudes before and after tests (Saic) are respectively 5.24 and 5.12 when faced with brand core value mismatching and significantly different $(P<0.05)$ which suggests that acquiring enterprise has 
brand dilution. This means that $\mathrm{H} 1$ and $\mathrm{H} 2$ are established (as shown in Table 1).

3) Moderating effect of construal level

Attitude difference before and after tests was used to verify $\mathrm{H} 3$ and $\mathrm{H} 4$ under the conditions of high construal level and low construal level. Firstly, average comparison of the attitude before and after tests has identified dilution effect. For subjects of high construal level, attitude before and after tests (Geely) are respectively 3.98 and 3.75 , and significantly different $(P<0.05)$ when brand images mismatch. It means that in high construal level, brand image mismatching results in acquiring enterprise brand dilution; attitude before and after tests (Saic) are respectively 4.27 and 4.14 , and significantly different $(P<0.05)$ when brand core values mismatch. It means that in high construal level, brand core values mismatching results in acquiring enterprise brand dilution.

Comparison of two kinds of dilution effect $(0.23$ and 0.13$)$ and significantly different $(P<0.05)$. In other words, in high construal level, acquiring enterprise brand dilution brand image mismatching cause is greater than the brand core value mismatching causes which supports H3 (as shown in Table 2).

For subjects of low construal level, attitude before and after test (Saic) are respectively 3.97 and 3.72, and significant difference $(P<0.05)$ when brand core values mismatch. It means that under low construal level, brand core values mismatching results in acquiring enterprise brand dilution; attitude before and after test (Geely) are respectively 3.78 and 3.65, and significant difference $(P<0.05)$ when brand images mismatch. It means that under low construal level, brand images mismatching results in acquiring enterprise brand dilution.

Comparison of two kinds of dilution effect $(0.25$ and 0.13$)$ and significant difference $(P<0.05)$. In other words, under low construal level, acquiring enterprises brand dilution brand core values mismatching cause is greater than the brand images mismatching causes which supports H4 (as shown in Table 2).

\section{Conclusions}

Experimental data show that in the cross-border M \& A brand image and core value dismatching between acquiring and target enterprises potentially reduce attitude or evaluation to acquiring enterprise brand, suggesting that cross-border M \& A is not always helpful to acquiring enterprise, brand mismatching may cause dilution.

In addition, effects brand mismatching causes to acquiring enterprise differ from consumers. In high construal level brand dilution image mismatching cause is greater than the brand core value mismatching cause to acquiring enterprise. In low construal level, brand dilution core value mismatching cause is greater than brand image mismatching cause, which means that enterprises should fully consider different target consumer groups when making decisions.

\section{Advice}

For cross-border M \& A which brand core values mismatch, acquiring enterprise can take measures to control the consumers' construal level and lead to abstract thinking. For cross-border M \& A which brand image mismatch, acquiring enterprise can guide consumers to take concrete thinking so as to enhance its awareness and improve evaluation or attitude to acquiring enterprise. Of course, this research also has some deficiencies and issues need to deepen:

1) Although MBA students have certain purchasing power, to a certain extent, it reduces external validity of research conclusion. In the future study, we should adopt diverse samples.

Table 1. Testing results of hypothesis 1 and 2.

\begin{tabular}{ccccc}
\hline Brand & Pre-test of cross-border M \& A & Post-test of cross-border M \& A & Dilution effect & Significance \\
\hline Geely & 4.29 & 3.78 & 0.51 & $P<0.05$ \\
Saic & 5.24 & 5.12 & 0.12 & $P<0.05$ \\
\hline
\end{tabular}

Table 2. Testing results of hypothesis 3 and 4 .

\begin{tabular}{ccccc}
\hline Brand & \multicolumn{2}{c}{ Acquiring enterprise } & Dilution effects & Significance \\
\hline Geely (HE/LE) & $3.98 / 3.78$ & $3.75 / 3.65$ & $0.23 / 0.13$ & $P<0.05$ \\
Saic (HE/LE) & $4.27 / 3.97$ & $4.14 / 3.72$ & $0.13 / 0.25$ & $P<0.05$ \\
\hline
\end{tabular}


2) Manipulation of construal level. We should focus on time distance, psychological distance influencing acquiring enterprise evaluation in the future study.

3) Target companies are from the United States and South Korea, whether the evaluation subjects are influenced by source image or other factors lead to brand dilution was not under good control. Its conclusion may not be applied to cross-border M\&A of other countries.

4) Cars have high degree of product involvement, will we get the same conclusion in the low degree of product involvement also needs further investigation.

\section{References}

[1] Li, H. and Wen, H.L. (2010) Effects Brands Matching on Brand Joint. Science and Technology Economic Market, 9, 84-86.

[2] Guohui, S. and Hao, J. (2014) The Effect of Brand Image Source on Multinational Joint. Journal of Economic Management, 7, 80-89.

[3] Liu, Y., Zhang, J.Y. and Du, Q.L. (2014) Match the Event Sponsors Brand Evaluation Study—Theory Perspective of Construal Level. Journal of Sports Science, 34, 4.

[4] Chai, J.W., Zhao, G.Z. and He, W. (2011) Effects of Construal Level on Brand Association and Brand Extension Evaluation. Journal of Psychology, 43,175-187.

[5] Li, Y.C., Zhang, T.R. and Zhou, X. (2009) Construal Level Theory: From Time Distance to Psychological Distance. Psychological Science Progress, 17, 667-677.

[6] Lane, K.K. (1993) Conceptualizing, Measuring and Managing Customer-Based Brand Equity. Journal of Marketing.

[7] Gwinner, K. and Eaton, J. (1999) Building Brand Image through Event Sponsorship: The Role of Image Transfer. Journal of Advertisement, 28, 47-57. http://dx.doi.org/10.1080/00913367.1999.10673595

[8] Vallacher, R.R. and Wegner, D.M. (1987) What Do People Think They Are Doing? Action Identification and Human Behavior. Psychological Review, 97, 3-15. http://dx.doi.org/10.1037/0033-295X.94.1.3

\section{Submit or recommend next manuscript to SCIRP and we will provide best service for you:}

Accepting pre-submission inquiries through Email, Facebook, Linkedin, Twitter, etc A wide selection of journals (inclusive of 9 subjects, more than 200 journals)

Providing a 24-hour high-quality service

User-friendly online submission system

Fair and swift peer-review system

Efficient typesetting and proofreading procedure

Display of the result of downloads and visits, as well as the number of cited articles

Maximum dissemination of your research work

Submit your manuscript at: http://papersubmission.scirp.org/ 